University of Nebraska - Lincoln

DigitalCommons@University of Nebraska - Lincoln

\title{
Dynamic and static characterization of compact crack arrest tests of navy and nuclear steels
}

James A. Joyce

US Naval Academy, jaj@usna.edu

R. E. Link

US Naval Academy, link@usna.edu

C. Roe

Naval Surface Warfare Center, charles.roe@navy.mil

J. C. Sobotka

University of Illinois at Urbana-Champaign, sobotkajc@gmail.com

Follow this and additional works at: https://digitalcommons.unl.edu/usnavyresearch

Joyce, James A.; Link, R. E.; Roe, C.; and Sobotka, J. C., "Dynamic and static characterization of compact crack arrest tests of navy and nuclear steels" (2010). U.S. Navy Research. 37.

https://digitalcommons.unl.edu/usnavyresearch/37

This Article is brought to you for free and open access by the U.S. Department of Defense at DigitalCommons@University of Nebraska - Lincoln. It has been accepted for inclusion in U.S. Navy Research by an authorized administrator of DigitalCommons@University of Nebraska - Lincoln. 


\title{
Dynamic and static characterization of compact crack arrest tests of navy and nuclear steels
}

\author{
James A. Joyce ${ }^{a, *}$, R.E. Link ${ }^{a}$, C. Roe ${ }^{b}$, J.C. Sobotka ${ }^{c}$ \\ a US Naval Academy, Annapolis, MD, USA \\ ${ }^{\mathrm{b}}$ Naval Surface Warfare Center, Carderock Division, Bethesda, MD, USA \\ ${ }^{\mathrm{c}}$ Civil Engineering Department, University of Illinois, Urbana, IL, USA
}

\section{A R T I C L E I N F O}

\section{Article history:}

Received 13 January 2009

Received in revised form 13 April 2009

Accepted 14 April 2009

Available online 21 April 2009

\section{Keywords:}

Crack arrest

Fracture toughness

Dynamic crack arrest

Stress intensity factor

$J$-integral

Ductile-to-brittle transition

Initiation toughness

HSLA-100

HY100

European round robin

Dynamic computational analysis

ASTM E1221

ASTM E1921

\begin{abstract}
A B S T R A C T
Recent experimental and computational work by Link and associates has demonstrated that relatively small $(W=150 \mathrm{~mm}$ ) single edge notched tension specimens $(\mathrm{SE}(\mathrm{T}))$ can be used to obtain crack arrest data high in the ductile-to-brittle transition of ferritic structural steel using dynamic computational techniques if a thermal gradient is utilized to aid in the crack arrest. Testing has been reported on two important navy structural steels that clearly defines the relative capability of the two materials to arrest rapidly growing cracks. The HY100 material demonstrated the expected large difference between the initiation and crack arrest toughnesses which has made it impossible in the past to measure crack arrest toughness for this material using the standard ASTM procedure (E1221). The HSLA-100 steel, however demonstrated a much higher crack arrest toughness and a correspondingly smaller drop in toughness below the initiation toughness. This small difference between initiation toughness and arrest toughness suggested that the E1221 procedure, using wedge loaded, compact crack arrest (CCA) specimens would be applicable to this material. Two important issues could then be investigated using this material. First, having completed the expensive and relatively complex testing of the $\mathrm{SE}(\mathrm{T})$ specimens using tensile loading and a thermal gradient, a second, quite different geometry could be tested using the E1221 procedure, allowing an important comparison between the crack arrest measurements made using these two distinct geometries. Historically, obtaining crack arrest results using one test configuration has been so difficult, that there have been very few reports of results for the same material using two different test geometries. Transferability of the laboratory results to structural applications has thus been a matter of conjecture. Furthermore, if the E1221 CCA specimens were strain gaged to obtain crack velocity data, and analyzed using the dynamic computational procedure used by Link on the SE(T) specimens, it would be possible to compare the results the E1221 static analysis with the results of the dynamic computation procedure to determine the degree of conservatism present in the E1221 standard procedure.

The results of this work have shown that the crack arrest toughness results obtained on these two specimen geometries are similar and hence insensitive to the test geometry and the difference resulting from the application of the complex dynamic computational procedure or the E1221 static analyses is small.
\end{abstract}

Published by Elsevier Ltd.

\footnotetext{
* Corresponding author.

E-mail addresses: jaj@usna.edu (J.A. Joyce), link@usna.edu (R.E. Link), charles.roe@navy.mil (C. Roe), sobotkajc@gmail.com (J.C. Sobotka).
} 


\section{Background}

The standard test method for measuring the crack arrest fracture toughness of ferritic steels is ASTM E1221 which specifies a wedge-loaded, compact crack arrest specimen with a falling K-field to promote crack arrest after a brittle crack is initiated from a notch or crack starter. The ASTM E1221 standard utilizes a static analysis of the compact crack arrest specimen to obtain an estimate of the crack arrest fracture toughness, $K_{I a}$, a short time after crack arrest (about $1 \mathrm{~ms}$ ). Based on work by Kalthoff and others $[1,2]$ it is assumed that the resulting crack arrest toughness is a conservative estimate of the true dynamic crack arrest toughness, but this assumption has not been verified and the degree of conservatism is not known.

The relatively small specimen size and the uniform specimen temperature used in the E1221 method restricts the application of the method to materials which have a modest initiation toughness and a small drop between initiation toughness and crack arrest toughness. Such properties are not ideal for structural applications. Modern structural design requires operation well up on the ductile-to-brittle transition or on the upper shelf and cleavage initiation is difficult to achieve. When a cleavage crack initiates, it is most likely at a relatively high fracture driving force and the crack often propagates completely across the specimen ligament. Brittle weld beads, as suggested by E1221, have been used successfully in some cases to initiate a brittle crack at a lower driving force which then propagates into the test material and arrests.

Many steels are not amenable to crack arrest testing using E1221 because they have a relatively high resistance to cleavage fracture initiation and a much lower crack arrest toughness. A schematic comparison of fracture initiation and arrest behaviors that allow crack arrest - Material A, or disallow crack arrest - Material B, tested using the E1221 method is shown schematically in Fig. 1. For Material A, a typical cleavage crack initiation $K_{J c}$ value results in a crack arrest $\left(K_{a}\right)$ value that is above the material lower shelf and corresponds to a change in stress intensity corresponding to a modest crack jump in the compact crack arrest specimen. For a material like Material B, low $K_{J c}$ values result in cracks that do not arrest until $a / W>0.8$ while higher $K_{J c}$ values do not initiate cleavage cracks, so in either case, no crack arrest toughness can be measured. The use of brittle weld beads to serve as crack starters may lower the initiation toughness but this can also lead to other complications such as the crack not extending past the heat affected zone of the brittle weld bead or turning abruptly at the weld baseplate interface. Additional difficulties that plague E1221 type crack arrest tests are the tendency of the growing crack to turn out of the specimen centerplane, a problem that seems to be most severe in the compact, wedge loaded specimen configuration used in the E1221 procedure. The tendency for a crack to curve has been linked to a positive T-stress [3] and the compact specimen has a relatively high positive T-stress.

Other crack arrest test methods have utilized large, 1-m wide tension geometries and dynamic finite element analysis to estimate the crack arrest toughness [4,5]. The tension configuration generally results in crack jumps in the desired plane, but the stress intensity magnitude generally increases with crack extension and a thermal gradient is required to stop the advancing crack. These large scale tests are generally prohibitively expensive. More recently, Link and co-workers [6-8] have reported on crack arrest tests using smaller $(150 \mathrm{~mm}$ wide), single, edge notch tension specimens, with a thermal gradient to obtain crack arrest toughness measurements in the mid to upper ductile-to-brittle transition region of ferritic HSLA-100 and HY100 alloy steels. Crack arrest fracture toughness was inferred from dynamic, 3D finite element analysis of the tests. The specimens were instrumented with strain gages to estimate the crack velocity allowing a dynamic, computational analysis of the crack arrest and to provide experimental data to validate the finite element analyses. The details of their dynamic computational analyses are presented fully in Refs. [6,7]. While the results for HY100 steel showed a $60^{\circ} \mathrm{C}$ difference between the crack initiation and crack arrest reference temperatures, the results for the HSLA-100 steel, presented in Fig. 2, show that the shift between the crack initiation and arrest reference temperatures was a much smaller shift of $31^{\circ} \mathrm{C}$, suggesting that isothermal tests following the E1221 procedure might be successful using this material.

Typically, crack arrest tests have been conducted on a single test geometry, generally using the E1221 compact crack arrest specimen, and analyzed statically. This test is very different from an expected structural crack arrest application in which tensile loading would predominate and thermal gradients are common. The magnitude of the degree of conservatism implicit in the static analysis is also not known.

There have also been questions raised that the dynamic crack arrest toughness measured using the $\operatorname{SE}(\mathrm{T})$ specimens may be different from the crack arrest toughness from a CCA specimen employing a static analysis to infer the crack arrest

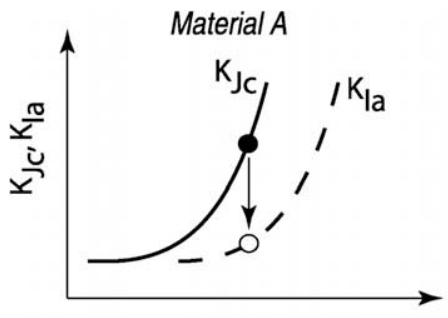

Temperature

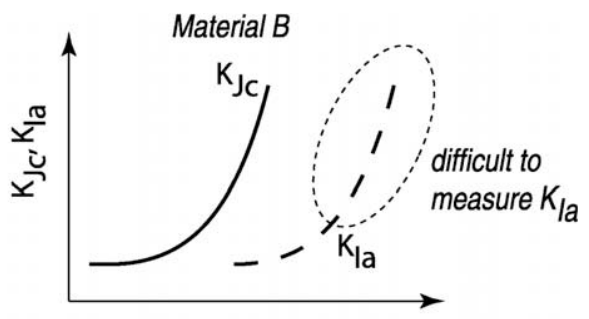

Temperature

Fig. 1. Schematic comparison of fracture toughness transition curves for two hypothetical materials with different shifts between the crack initiation and arrest fracture toughness. 


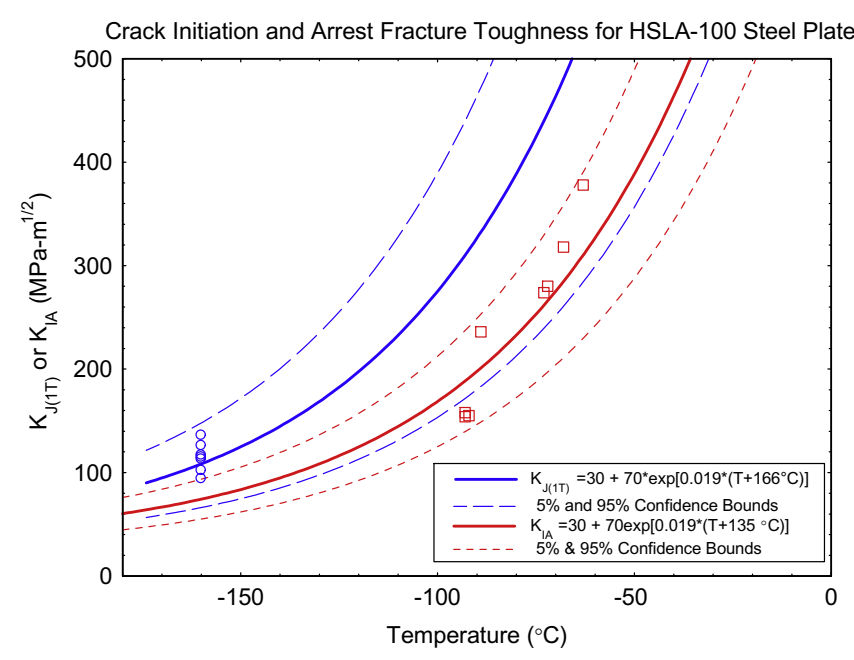

Fig. 2. Dynamic crack arrest results obtained for HSLA-100 steel using small scale SE(T) specimens including a thermal gradient and initiation toughness test results from $\mathrm{C}(\mathrm{T})$ specimens for HSLA-100 steel.

toughness. The effects of specimen geometry and crack tip constraint on the crack arrest toughness have also been raised as potential issues. Independent crack arrest tests on two different geometry specimens using the same material utilizing both the E1221 procedure and a dynamic computational procedure would be useful to demonstrate that the two procedures are not dependent on the crack tip and remote loading configurations. Likewise having both static and dynamic analyses of the two different geometries would further validate the use of the static E1221 method and give some information on the magnitude of the conservatism resulting from the use of the static analysis.

Testing was also conducted in this study on a DIN 22NiMoCr37 pressure vessel steel forging using two sizes of CCA specimen geometry and including both dynamic and static analyses. This material is the so called "Euro forging material" that has been used in the extensive master curve round robin reported by Heerens et al. [9]. No SE(T) results are available at present for this steel.

\section{Analysis}

\subsection{Crack arrest master curve}

Laboratory crack arrest tests can only be conducted over a narrow temperature range which is from the low to the mid transition for the ferritic steel's ductile-to-brittle transition for cleavage initiation and then hopefully only slightly above the lower shelf for the steel's crack arrest toughness transition. This case was presented schematically in Fig. 1a, above. Transferring test results obtained over this range of temperatures to the application requires a curve fitting and extrapolation procedure of some type. A recent proposal of Wallin and Rintamaa [10], based on the cleavage initiation Master Curve, involves fitting the experimentally measured $K_{I a}$ data with an equation of the form:

$$
K_{\text {Ia(med) }}=30+70 \exp \left[0.019\left(T-T_{K_{I a}}\right)\right]
$$

where $T_{K_{I a}}$ is the temperature where the median $K_{I a}=100 \mathrm{MPa} \mathrm{m}^{1 / 2}$. The crack arrest reference temperature can be calculated using a maximum likelihood approach from [11]:

$$
\sum_{i=1}^{n} \frac{\ln K_{i} \cdot \exp \left\{0.019\left[T_{i}-T_{K_{I}}\right]\right\}}{30+70 \cdot \exp \left\{0.019\left[T_{i}-T_{K_{l a}}\right]\right\}}-\sum_{i=1}^{n} \frac{\ln \left(30+70 \cdot \exp \left\{0.019\left[T_{i}-T_{K_{I a}}\right]\right\}\right) \cdot \exp \left\{0.019\left[T_{i}-T_{K_{I a}}\right]\right\}}{30+70 \cdot \exp \left\{0.019\left[T_{i}-T_{K_{I}}\right]\right\}}=0
$$

where $K_{i}$ is the arrest toughness at $T_{i}$ for the $i$ th specimen and $n$ is the number of specimens. The standard deviation, $\sigma$, on the distribution of $K_{I a}$ is given by:

$$
\sigma^{2}=\frac{\sum_{i=1}^{n}\left\{\ln K_{i}-\ln \left(30+70 \cdot \exp \left\{0.019\left[T_{i}-T_{K_{l a}}\right]\right\}\right)\right\}^{2}}{n}
$$

This fitting procedure is different from that specified in ASTM E1921 for the cleavage initiation master curve reference temperature, $T_{0}$, because Wallin and Rintamaa assume the crack arrest data follow a log-normal distribution rather than a Weibull distribution [10]. 
Table 1

Chemical composition of the HSLA-100 and Euro forging steels.

\begin{tabular}{|c|c|c|}
\hline Element & HSLA-100, comp. 3 & Euro forging \\
\hline $\mathrm{C}$ & 0.05 & 0.21 \\
\hline $\mathrm{Mn}$ & 0.82 & 0.82 \\
\hline $\mathrm{P}$ & 0.010 & 0.003 \\
\hline S & 0.003 & 0.004 \\
\hline $\mathrm{Si}$ & 0.35 & 0.24 \\
\hline $\mathrm{Cu}$ & 1.61 & 0.049 \\
\hline $\mathrm{Ni}$ & 3.41 & 0.79 \\
\hline $\mathrm{Cr}$ & 0.55 & 0.003 \\
\hline Mo & 0.60 & 0.56 \\
\hline $\mathrm{N}$ & 0.008 & - \\
\hline $\mathrm{Cb}$ & 0.03 & - \\
\hline
\end{tabular}

Table 2

Room temperature tensile mechanical properties for the HSLA-100 and Euro forging steels.

\begin{tabular}{lll}
\hline & HSLA-100, comp.3, plate GQN \\
\hline Ultimate tensile strength (MPa) & 827 \\
Yield strength (MPa) & 765 \\
Elongation in 51 mm (\%) & 37 \\
Reduction in area (\%) & 60 \\
\hline
\end{tabular}

\section{Experiments}

\subsection{Materials description}

The materials used in this investigation were a 19 mm thick, HSLA-100, Composition 3, steel plate and a DIN 22 NiMoCr37 pressure vessel steel forging (the Euro forging), which is similar to an A508 Class 3 pressure vessel steel, approximately $240 \mathrm{~mm}$ thick. The chemical composition of these steels and the room temperature tensile mechanical properties are listed in Tables 1 and 2. Further information is available on the Euro material in Ref. [9]. Fracture toughness tests of each plate were conducted to determine the reference temperature, $T_{0}$, in accordance with ASTM E1921. For the HSLA-100 plate, seven 3/4T, $\mathrm{C}(\mathrm{T})$ specimens $\left(W=38 \mathrm{~mm}, B=18 \mathrm{~mm}\right.$ ) were tested at a temperature of $-160{ }^{\circ} \mathrm{C}$. The reference temperature, $T_{0}$ was determined to be $-166{ }^{\circ} \mathrm{C}$ for the HSLA-100 plate. For the Euro forging material the reference temperature was taken from Wallin [12] with a conscious eye toward the extensive inhomogeneity study done on this material by Joyce [13]. For this material, an average $T_{0}$ from the extensive European round robin was shown to be $-94{ }^{\circ} \mathrm{C}$, but the variation resulting from the large section size of this forging gives a range of reference temperatures from $-72{ }^{\circ} \mathrm{C}$ to $-125^{\circ} \mathrm{C}$.

\section{Specimen details}

\subsection{CCA specimens}

Two sizes of compact crack arrest specimens were used in this study for the HSLA-100 steel and for the Euro forging, $W=120 \mathrm{~mm}$ and $W=50 \mathrm{~mm}$. These specimens were tested isothermally, enclosed in a test chamber, and wedge loaded as is typical of ASTM E1221 tests, see Fig. 3. Tests were conducted on these specimens according to E1221 using fatigue pre-cracks introduced in the specimens according to the specifications of E1921. Strain gage rosettes were applied to both surfaces of some of the $W=120 \mathrm{~mm}$ specimens, offset above and below the crack plane, to obtain crack velocity data for use in the dynamic FEA analysis of these specimens.

\subsection{Dynamic analysis of the CCA specimen geometry}

In order to compare the dynamic analysis of the $\mathrm{SE}(\mathrm{T})$ specimens to the static analysis of E1221, CCA specimens typical of E1221 were strain gaged as required by the dynamic analysis, and tested using the methodology of E1221. The results were analyzed in accordance with the static analysis described in E1221 as well as a full 3-D dynamic analysis using finite elements. The CCA specimens were wedge loaded and the strain gages measurements were used to estimate the crack speed and position during the crack run-arrest event. The HSLA-100 material was chosen for these tests because of the small difference measured between $T_{0}$ and $T_{K_{I a}}$ determined from previous tests [7], which appeared to allow the use of $W=120 \mathrm{~mm}$ CCA specimens for E1221 type tests. These results will be discussed in more detail below.

Finite element analysis was used to model the crack arrest tests and to determine the dynamic crack arrest fracture toughness. The finite element code, WARP3D, was used to perform the analyses [14]. A detailed description of the develop- 


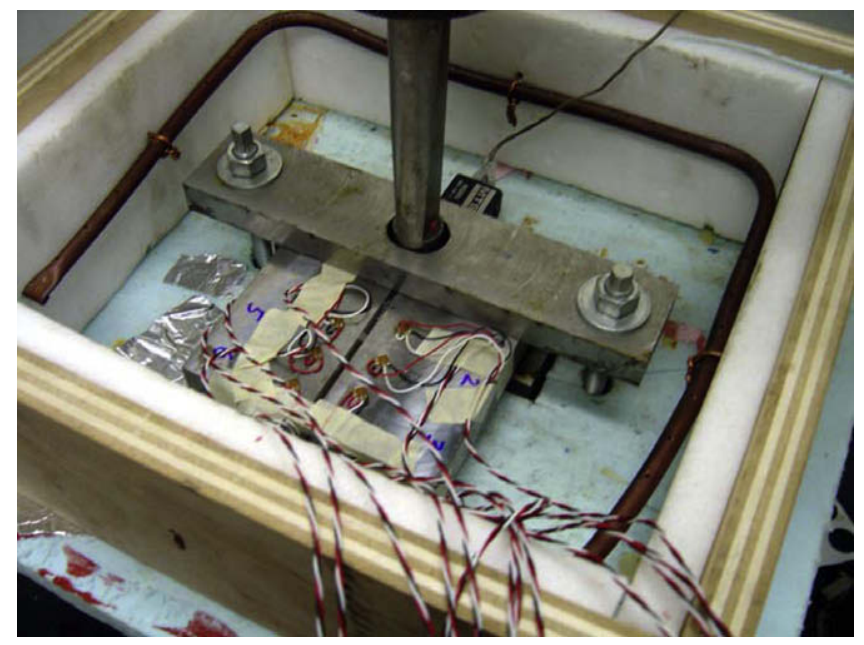

Fig. 3. Test apparatus for an isothermal, wedge loaded, CCA specimen, $W=120 \mathrm{~mm}$ (shown with the chamber cover removed). Additional strain gages are mounted on the bottom face of the specimen.

ment and validation of the models used is available in previous publications [5-7]. The material constitutive behavior employed a von Mises yield criterion with isotropic hardening. A power-law visco-plastic material model was used to characterize the strain-rate sensitivity of the steel. The relationship is:

$$
\dot{\varepsilon}_{v p}=\frac{1}{D}\left[\left(\frac{q}{\sigma_{e}}\right)^{m}-1\right]
$$

where $\dot{\varepsilon}_{v p}$ is the strain rate, $q$ is the rate dependent stress, $\sigma_{e}$ is the inviscid uniaxial stress and $D$ and $m$ are temperature independent, material specific constants determined from fitting the high-rate stress-strain curves. The temperature dependence of the visco-plastic response enters through the inviscid uniaxial stress, $\sigma_{e}$, which is a function of temperature. The parameters determined from fitting the HSLA-100 test results were $D=1.0 \mathrm{~mm} / \mathrm{mm} / \mathrm{s}$ and $m=125$. The power-law exponent of 125 represents a relatively low sensitivity to strain rate. A piecewise-linear, isothermal stress-strain curve, measured at the specimen temperature at the point of crack arrest, was used to characterize $\sigma_{e}$ as a function of the visco-plastic strain, $\varepsilon_{\mathrm{vp}}$, was used for each material.

Displacement boundary conditions were applied to the nodes at the top of the hole where the split-pin contacts the specimen. The displacement was increased monotonically until the CMOD in the FE model was equal to the CMOD measured at crack initiation in the specimen. The displacements at the top of the pinhole were held constant during the dynamic crack propagation phase. Dynamic crack growth was modeled by using a prescribed node-release technique wherein an equivalent reaction force replaced the displacement constraint at the crack tip and the reaction force was linearly relaxed to zero over a fixed number of time steps. This is a generation-mode analysis where the crack length vs. time history, obtained from experiment, is explicitly enforced as a known boundary condition.

The 3D finite element grid used to analyze the CCA specimen geometry is shown in Fig. 4 and contained approximately 22,000 nodes and 17,500 elements. It had 5 layers of elements through the half-thickness and the elements along the crack plane were $0.5 \mathrm{~mm}$ long. The sidegroove geometry was included in the model. The analysis assumed that the crack front was
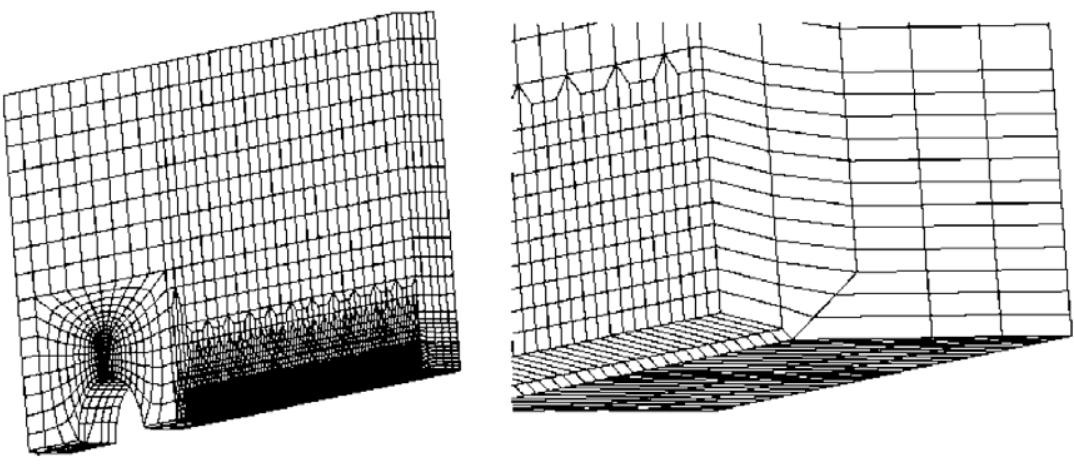

Fig. 4. Finite element mesh used for CCA specimen. 
straight and uniform through the specimen thickness. Even though the actual crack fronts in the specimens exhibited some tunneling, the analysis in E1221 and the crack speed inferred from the strain signals both assume an effective straight crack front. The domain integral technique was used to calculate the dynamic J-integral averaged over the crack front. A throughthickness average value of $J$ was used in all of the 3D results reported herein. All $J$-integral values were converted to equivalent stress intensity factor, $K$, using the relationship:

$$
K=\sqrt{\frac{J E}{\left(1-v^{2}\right)}}
$$

Cleavage cracks arrest very abruptly from a speed of several hundred meters/seconds to zero over a very short distance. Computational studies examined the effect of the crack velocity profile over the final crack growth increment. These studies determined that the dynamic value of the crack arrest toughness was less sensitive to the shape of the velocity profile $0.5 \mu \mathrm{s}$ after the release of all reactions forces along the crack plane compared with the value at the instant of releasing the last increment of force. Consequently, all computational analyses of the CCA specimens defined the value of $K_{I a}$ in this manner.

\section{Discussion of the results}

\subsection{HSLA-100 steel}

Two sets of CCA specimens were prepared in the T-L orientation from the broken HSLA-100 SE(T) specimens. The first set of eight specimens had $W=50.8 \mathrm{~mm}$ and these specimens were tested at $-160^{\circ} \mathrm{C}$ and were analyzed using the E1221 approach. These results are tabulated in Table 3. The crack arrest results for the $W=50.8 \mathrm{~mm}$ CCA specimens using the E1221 static analysis are compared with the dynamic analysis crack arrest results from the $\mathrm{SE}(\mathrm{T})$ specimens obtained in a previous study for this material [7] in Fig. 5. Because the first set of specimens were precracked, it was also possible to measure $K_{I c}$ according to E1921 for these tests and the initiation toughness values are also plotted in Fig. 5.

The second set of 7 CCA specimens had $W=120 \mathrm{~mm}$ and were tested at temperatures of -160 and $-150{ }^{\circ} \mathrm{C}$, near the initiation reference temperature for the material, $T_{0}=-166{ }^{\circ} \mathrm{C}$. These specimens were also instrumented with strain gage

Table 3

Cleavage initiation and crack arrest toughness for HSLA-100 CCA specimens $(W=50.8 \mathrm{~mm})$

\begin{tabular}{lllll}
\hline Specimen ID & $W(\mathrm{~mm})$ & Test temperature $\left({ }^{\circ} \mathrm{C}\right)$ & $K_{J c}$ E1921 $\left(\mathrm{MPa}-\mathrm{m}^{1 / 2}\right)$ & $K_{I a} \mathrm{E}^{1221}\left(\mathrm{MPa}-\mathrm{m}^{1 / 2}\right)$ \\
\hline GQNCCA-2 & 50.8 & -160 & 160.7 & 60.6 \\
GQNCCA-3 & 50.8 & -160 & 153.6 & 70.2 \\
GQNCCA-4 & 50.8 & -160 & 60.9 & 36.3 \\
GQNCCA-6 & 50.8 & -160 & 115.8 & 63. \\
GQNCCA-8 & 50.8 & -160 & 134.8 & 66.4 \\
GQNCCA-9 & 50.8 & -160 & 165.6 & 71.8 \\
GQNCCA-10 & 50.8 & -160 & 148.4 & 79.3 \\
GQNCCA-12 & 50.8 & -160 & 120.0 & 62.1 \\
\hline
\end{tabular}

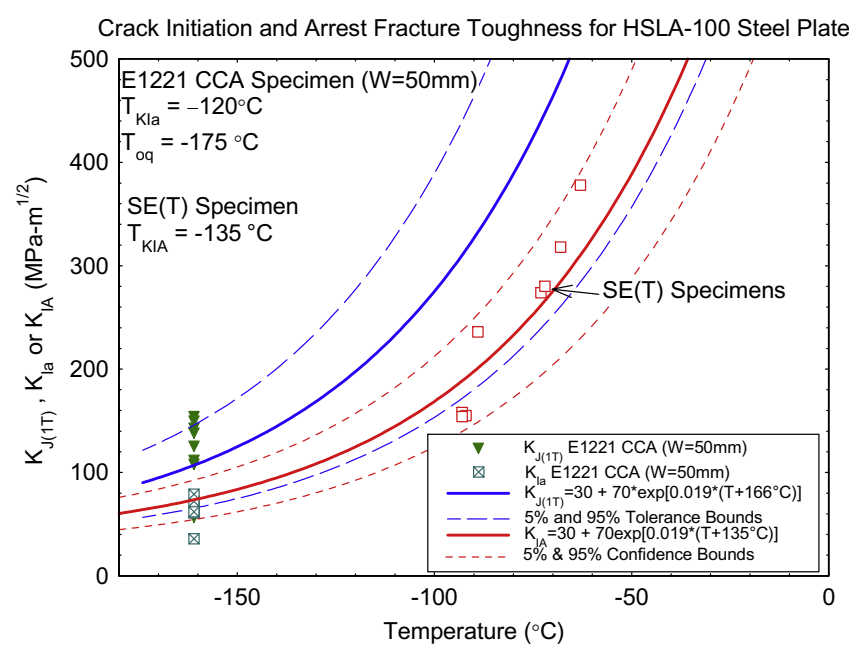

Fig. 5. Crack initiation and arrest toughness of HSLA-100 from $1 \mathrm{~T}(W=50 \mathrm{~mm})$ CCA specimens compared with master curves for HSLA-100. 
rosettes in a manner similar to the $\mathrm{SE}(\mathrm{T})$ specimens and the strain gage data was used to prescribe the crack position and velocity in a dynamic finite element analysis, as done previously for the $\mathrm{SE}(\mathrm{T})$ specimens [6,7], and the results are tabulated in Table 4 and compared with the results of the $\mathrm{SE}(\mathrm{T})$ specimens in Fig. 6.

The reference temperature for crack initiation determined from the eight CCA specimens was $T_{0 q}=-175^{\circ} \mathrm{C}$, which was $9{ }^{\circ} \mathrm{C}$ lower than that determined from standard $\mathrm{C}(\mathrm{T})$ specimens in accordance with E1921. Part of the difference could be attributed to the shallower initial crack size in the CCA specimens and part of the difference may be normal scatter.

The crack arrest reference temperature determined from the set of $W=50.8 \mathrm{~mm}$ specimens was $-119{ }^{\circ} \mathrm{C}$, which is $16^{\circ} \mathrm{C}$ warmer that the $-135{ }^{\circ} \mathrm{C}$ reference temperature measured using the $\mathrm{SE}(\mathrm{T})$ specimens with a dynamic analysis. It should be noted that one of the specimens exhibited very low initiation toughness and consequently had a very low arrest value. If this specimen was considered an outlier, then the adjusted $T_{K_{l a}}$ for the $W=50.8 \mathrm{~mm}$ CCA specimens is $-127{ }^{\circ} \mathrm{C}$.

The crack arrest toughness for the $W=120 \mathrm{~mm}$ specimens was determined using the static analysis of E1221 and also from dynamic FEA using the crack velocity information from the strain gages. The average crack velocity in all of these tests was $380 \mathrm{~m} / \mathrm{s}$, which is similar to the crack speeds observed in the $\mathrm{SE}(\mathrm{T})$ specimens which were tested at higher temperatures. The results tabulated in Table 4 show slight differences between the static and dynamic calculations of the crack arrest toughness for individual specimens. The maximum difference observed was $21 \%$ for specimen GQN-TL5C. There is no systematic trend between the static and dynamic toughness calculations. The averages of both the static and dynamic crack arrest toughness are identical. The dynamic results ranged both higher and lower than the static results. It is interesting to note that despite the differences in the specific crack arrest toughness values, both calculation approaches yield equivalent crack arrest reference temperatures of $T_{K_{l a}}=-136^{\circ} \mathrm{C}$ which is nearly the same value $\left(-135^{\circ} \mathrm{C}\right)$ obtained from the $\operatorname{SE}(\mathrm{T})$ specimens with the thermal gradients. The full set of crack arrest toughness results for the HSLA-100 alloy steel is plotted in Fig. 6. The overall trend in toughness as a function of temperature is well represented by the crack arrest master curve and both the $\mathrm{SE}(\mathrm{T})$ specimens with a thermal gradient and the CCA specimens lie on the same crack arrest reference curve.

Table 4

Comparison of static analysis (E1221) and dynamic analysis results for the HSLA-100 CCA (W=120 mm) specimen tests.

\begin{tabular}{|c|c|c|c|c|}
\hline Specimen test & Temperature $\left({ }^{\circ} \mathrm{C}\right)$ & $W(\mathrm{~mm})$ & $K_{I a} \mathrm{E} 1221\left(\mathrm{MPa}-\mathrm{m}^{1 / 2}\right)$ & $K_{I a}$ FEA $\left(\mathrm{MPa}-\mathrm{m}^{1 / 2}\right)$ \\
\hline GQN-TL4C \# 1 & -160 & 120 & 65.9 & 69.1 \\
\hline GQN-TL4C \# $2^{\mathrm{a}}$ & -160 & 120 & 58.5 & 64.8 \\
\hline GQN-TLXC & -160 & 120 & 76.4 & 86.1 \\
\hline GQN-TL7C & -150 & 120 & 73.5 & 71.8 \\
\hline GQN-TL7AC & -150 & 120 & 65.7 & 67.7 \\
\hline GQN-TL5C ${ }^{\mathrm{b}}$ & -150 & 120 & 87.8 & 69.6 \\
\hline GQN-TLYC & -150 & 120 & 77.1 & 73.8 \\
\hline GQN-TL4AC \# $1^{\mathrm{b}}$ & -150 & 120 & 80.2 & 75.6 \\
\hline GQN-TL4AC \# $2^{\mathrm{a}}$ & -150 & 120 & 79.3 & 87.4 \\
\hline$T_{K_{\text {la }}}\left({ }^{\circ} \mathrm{C}\right)$ & & & -136 & -136 \\
\hline
\end{tabular}

\footnotetext{
a Short crack jump, specimen tested twice.

b Strain gage data not recorded, velocity assumed.
}

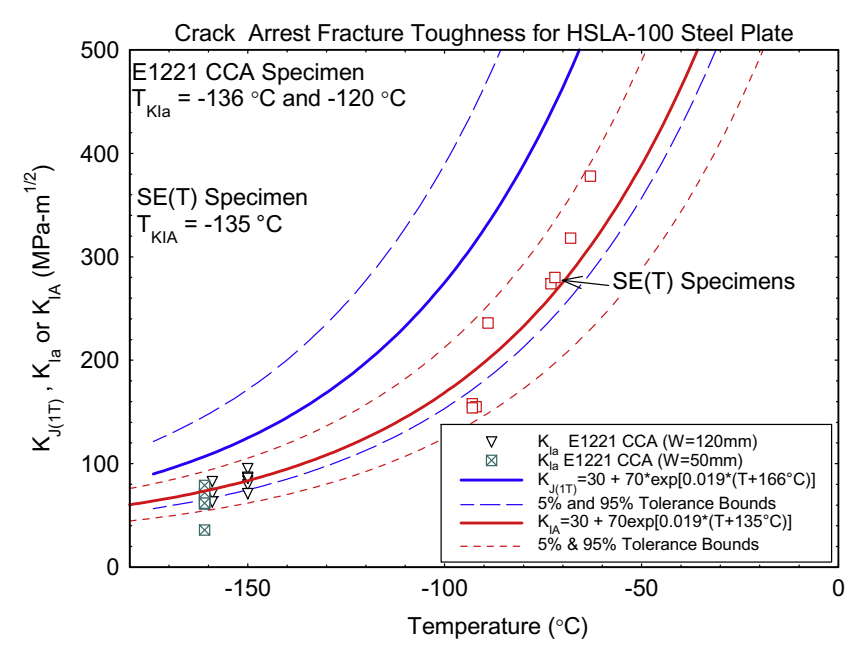

Fig. 6. Crack arrest toughness of HSLA-100 determined from CCA specimens compared with master curves. 


\subsection{Euro forging steel}

Two sets of CCA specimens with $W=43-44 \mathrm{~mm}$ and $W=112 \mathrm{~mm}$ were prepared in the T-S orientation from a piece of the Euro forging. Standard crack arrest tests using precracked specimens were conducted in accordance with E1221 at temperatures from $-120^{\circ} \mathrm{C}$ to $-80^{\circ} \mathrm{C}$, close to the crack initiation reference temperature for this material, $T_{0}=-94^{\circ} \mathrm{C}$. The $W=112 \mathrm{~mm}$ specimens were instrumented with strain gages to determine the crack velocity for input into the dynamic finite element analyses of these tests. Successful crack arrest was achieved in twelve of the eighteen $W=44 \mathrm{~mm}$ specimens and in five of the eight $W=112 \mathrm{~mm}$ specimens. At the lowest temperatures, the cracks either ran too far through the specimen or branched after a few millimeters of brittle crack extension. The results from the E1221 analysis of these tests are plotted in Fig. 7. The crack arrest reference temperature, $T_{K_{l a}}$, was calculated to be $-10^{\circ} \mathrm{C}$ for this material.

Strain gage data was successfully recorded for two of the $W=112 \mathrm{~mm}$ specimens and dynamic finite element analysis was performed for those tests. In one case, the predicted strains showed fairly good agreement with the measured strain signals as shown in Fig. 8 for specimen EUR-4A. However, the dynamic crack arrest toughness was calculated to be $25 \%$ lower than that computed using the E1221 procedure, $32-43 \mathrm{MPa}-\mathrm{m}^{1 / 2}$ at $-95^{\circ} \mathrm{C}$. The calculated crack driving force history is plotted in Fig. 9. The large difference between the FEA predictions and the static calculations is due in part to the large increase in CMOD measured on the specimen during the run-arrest event. The brittle fracture initiated at a CMOD $=0.48 \mathrm{~mm}$ and the CMOD increased an additional 50\% after initiation. This large increase in CMOD was not predicted in the finite element analysis, nor was it observed in any of the other tests. In fact, the FEA predicted a very slight decrease in CMOD for this test. If the

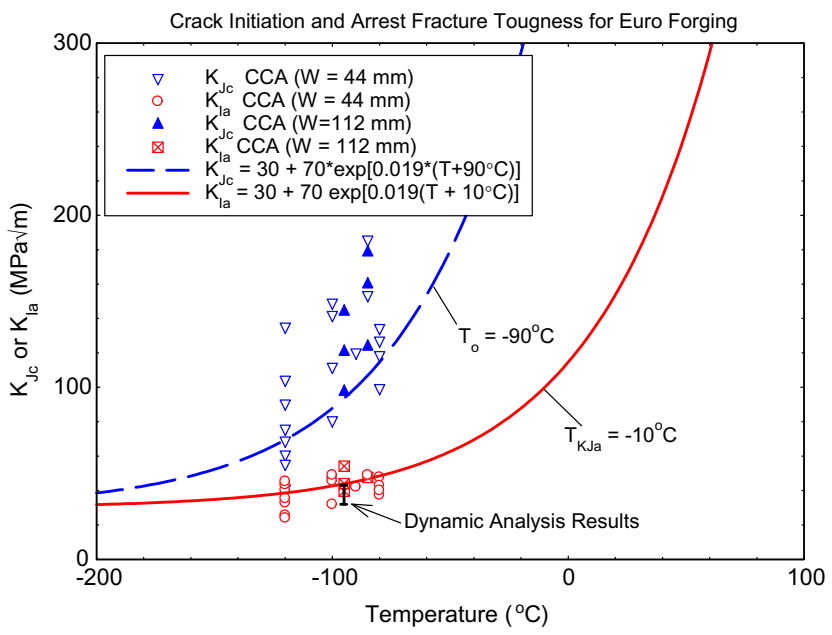

Fig. 7. Summary of E1221 static crack arrest results for the Euro forging material.

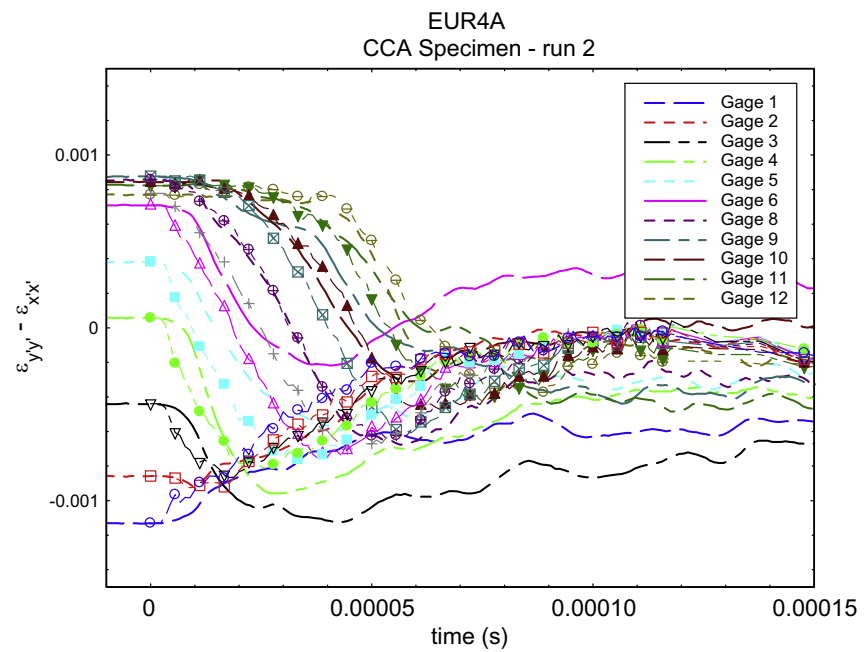

Fig. 8. Comparison of the measured and predicted strains for a Euro material CCA specimen. The curves with the symbols are the predicted response. 


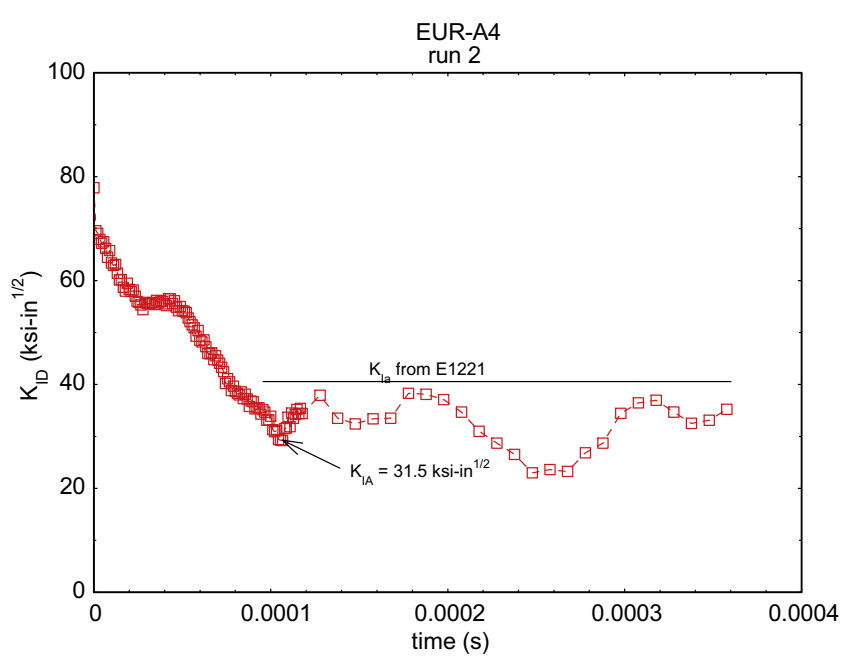

Fig. 9. The predicted dynamic crack driving force vs. time for specimen EUR-4A compared with $K_{I a}$ determined using E1221 approach.

CMOD was assumed to remain constant during the run-arrest event, there is much better agreement between the dynamic FEA value of crack arrest toughness and the E1221 value with $K_{I a}=35.8 \mathrm{MPa}-\mathrm{m}^{1 / 2}$ which is much closer to the value of $32 \mathrm{MPa}-\mathrm{m}^{1 / 2}$ from the finite element analysis.

For the second specimen, there was rather poor agreement between the predicted and measured strains but good agreement between the crack arrest toughness computed using the static approach and the dynamic FEA predictions, 49 (dynamic) and $46.8 \mathrm{MPa}-\mathrm{m}^{1 / 2}$.

\subsection{Initiation-arrest relationship}

Wallin [9] developed an empirical relationship between the crack initiation reference temperature, $T_{0}$, and the shift between the crack initiation and crack arrest reference temperatures, $T_{K_{I a}}-T_{0}$, by analyzing the results of many crack arrest tests in the literature. For the original model, all steels had a nickel content less than $1.2 \%$. A subsequent model [14] included the effect of additional nickel on the shift. The results presented in this paper are plotted vs. the model and original data used to develop the relationship in Fig. 10. The models do a respectable job of predicting the shift in the reference temperature. For the Euro forging material, it is worth noting that there was considerable variability in the $T_{0}$ values reported for this forging with results ranging from $-125^{\circ} \mathrm{C}$ to $-72^{\circ} \mathrm{C}[12-13]$.

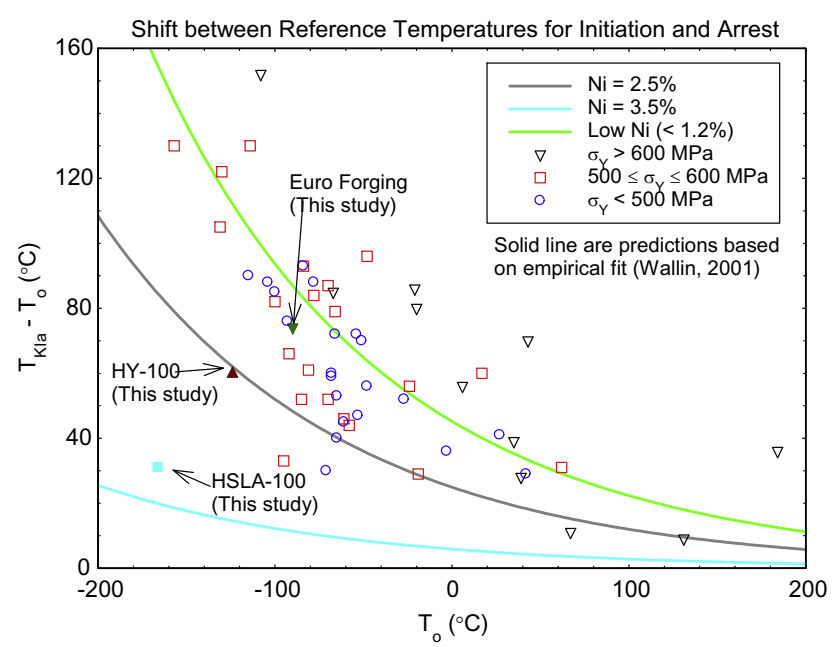

Fig. 10. The predicted shift in reference temperature between crack initiation and arrest as afunction of the reference temperature along with the results from this study. 
Table 5

Cleavage initiation and crack arrest toughness for the Euro forging specimens.

\begin{tabular}{|c|c|c|c|c|}
\hline Specimen ID & $W(\mathrm{~mm})$ & Test temperature $\left({ }^{\circ} \mathrm{C}\right)$ & $K_{J c}$ E1921 (MPa-m $\left.{ }^{1 / 2}\right)$ & $K_{I a} \mathrm{E} 1221\left(\mathrm{MPa}-\mathrm{m}^{1 / 2}\right)$ \\
\hline Eur22A & 44.4 & -120 & 60.7 & 33.0 \\
\hline Eur14A & 44.4 & -120 & 90.5 & 40.3 \\
\hline Eur20A & 44.4 & -120 & 68.9 & 35.5 \\
\hline Eur8B & 44.4 & -120 & 135.2 & - \\
\hline Eur6A & 44.4 & -120 & 104.3 & 48.5 \\
\hline Eur4A & 44.4 & -120 & 40.9 & 25.6 \\
\hline Eur2B & 44.4 & -120 & 55.4 & 24.1 \\
\hline Eur2A & 44.4 & -120 & 75.8 & - \\
\hline Eur18A & 44.4 & -100 & 149.2 & 52.0 \\
\hline Eur4B & 44.4 & -100 & 80.6 & 35.2 \\
\hline Eur14B & 44.4 & -100 & 111.8 & 50.2 \\
\hline Eur6B & 44.4 & -100 & 133.8 & 51.2 \\
\hline Eur22Ax & 43.2 & -80 & 139.8 & - \\
\hline Eur8A & 44.4 & -85 & 186.0 & - \\
\hline Eur6Cx & 43.2 & -80 & 130.4 & 47.1 \\
\hline Eur20Ax & 43.2 & -80 & 147.6 & - \\
\hline Eur20Cx & 43.2 & -80 & 109.2 & 41.1 \\
\hline Eur22Cx & 43.2 & -90 & 132.0 & - \\
\hline EurB3 & 112 & -85 & 176.1 & - \\
\hline EurA3 & 112 & -85 & 197.0 & - \\
\hline EurB1 & 112 & -85 & 136.4 & - \\
\hline EurA5 & 112 & -95 & 107.4 & 43.5 \\
\hline EurB4 & 112 & -95 & 133.0 & 48.5 \\
\hline EurA1 & 112 & -95 & 158.6 & 59.6 \\
\hline EurB2 & 112 & -95 & 140.5 & 46.9 \\
\hline EurA4 & 112 & -95 & 86.0 & 44.4 \\
\hline
\end{tabular}

\section{Discussion}

There was good agreement between the crack arrest reference temperature, $T_{K_{l a}}$, determined using the $\mathrm{SE}(\mathrm{T})$ specimens and the CCA specimens with the HSLA-100 steel. The reference temperatures from the SE(T) and CCA specimens with $W=120 \mathrm{~mm}$ were identical and the reference temperature from the $W=50 \mathrm{~mm}$ CCA specimens was elevated by comparison by $9-16{ }^{\circ} \mathrm{C}$. This supports the assumption that the crack arrest toughness measured in these tests is insensitive to the specimen geometry and provides some assurance that transfer of these crack arrest results to structural applications is possible (see Table 5).

The test temperatures used for the crack arrest tests on the Euro material were well below the crack arrest reference temperature, from 64 to $104{ }^{\circ} \mathrm{C}$ below the calculated $T_{K_{l a}}$ of $-10{ }^{\circ} \mathrm{C}$. The accuracy of $T_{K_{l a}}$ is questionable because the reference temperature is very sensitive to small changes in the mean toughness at very low temperatures. Improved measurement of the crack arrest toughness for this material requires testing using the $\mathrm{SE}(\mathrm{T})$ specimen and a thermal gradient so that crack arrest toughness higher in the ductile-to-brittle transition can be obtained.

It should be noted that there is no standardized method for determining $T_{K_{l a}}$ but all data for determining the initiation reference temperature, $T_{0}$, must be from tests conducted within $50{ }^{\circ} \mathrm{C}$ of the reference temperature. The minimum number of data points required for determination of $T_{0}$ is also dependent on the specimen test temperature.

The comparison between the dynamic crack arrest toughness calculated using finite element analysis of the experiment and that using a static analysis from E1221 yielded similar average crack arrest toughness for the HSLA-100 and Euro specimens. These results reinforce the earlier experimental and 2D finite element analyses that originally proposed that a static analysis was sufficient for analyzing the CCA specimen.

\section{Conclusions}

Application of the dynamic finite element analysis to isothermal ASTM E1221 compact crack arrest specimens of HSLA100 steel was successful, resulting in an average crack arrest master curve reference temperature identical to that obtained using the static E1221 analysis. This result provide a valuable linkage between the dynamic SE(T) test analysis and the standard, static analysis of E1221.

For the HSLA-100 steel, the measured average crack arrest master curve reference temperature obtained using from the $W=120 \mathrm{~mm}$ CCA specimens using either static or dynamic analyses was essentially identical with the average crack arrest master curve reference temperature obtained in previous work from the dynamic $\mathrm{SE}(\mathrm{T})$ tests. The average crack arrest master curve reference temperature obtained using the smaller $W=50.8 \mathrm{~mm}$ CCA specimens was $16{ }^{\circ} \mathrm{C}$ higher than that obtained from the larger CCA tests and dynamic SE(T) tests. All except 1 of the 24 HSLA-100 CCA specimen tests fell within the $95 \%$ tolerance bounds of the $T_{K_{l a}}$ master curve based on the larger CCA or SE(T) analyses. 
Dynamic analysis of CCA specimens of the Euro material was less successful due to the large additional crack opening that occurred prior to arrest in one of the specimens. This behavior was not commonly observed in other tests and it was not predicted in the finite element analysis. For the Euro forging steel, the results of the dynamic analysis were in general agreement with the results of the E1221 static analysis. Since only CCA specimens were available, all crack arrest data were obtained very low in the ductile-to-brittle transition. To better characterize crack arrest in this material some $\mathrm{SE}(\mathrm{T})$ testing should be conducted utilizing a thermal gradient to obtain crack arrest data higher in the ductile-to-brittle transition.

\section{Acknowledgments}

This project was sponsored by the US Navy and by the US Nuclear Regulatory Commission Office of Nuclear Regulatory Research under the direction of Dr. Mark Erickson-Kirk. The assistance of the Technical Support Department of the US Naval Academy is also gratefully acknowledged.

\section{References}

[1] Kalthoff JF, Beinert J, Winkler S, Klemm W. Experimental analysis of dynamic effects in different crack arrest test specimens. In: Hahn GT, Kanninen MF, editors. Crack arrest methodology and applications. ASTM STP 711. American Society for Testing and Materials; 1980. p. $109-27$.

[2] Kobayashi T, Dally JW. Dynamic photoelastic determination of the a(dot)-K relation for 4340 alloy steel. In: Hahn GT, Kanninen MF, editors. Crack arrest methodology and applications. ASTM STP 711. American Society for Testing and Materials; 1980 . p. 189-210.

[3] Ramulu M, Kobayashi A. Mechanics of crack curving and branching - a dynamic fracture analysis. Int J Fracture 1985;27:187-201.

[4] Naus DJ et al., Crack-arrest behavior in SEN wide plates of quenched and tempered A533 grade B steel tested under nonisothermal conditions, NUREG/ CR-4930, US Nuclear Regulatory Commission, Washington, DC; August 1987.

[5] Naus DJ, Keeney-Walker J, Bass BR, Bolt SE, Fields RJ, deWitt R, et al. High-temperature crack-arrest behavior in 152-mm-thick SEN wide plates of quenched and tempered A533 grade B class 1 steel, NUREG/CR-5330, US Nuclear Regulatory Commission, Washington, DC; April 1989.

[6] Link RE. Analysis of dynamic fracture and crack arrest of an HSLA steel in an SE(T) specimen. J ASTM Int 2006;3(1). Paper ID JAI13236.

[7] Link RE, Roe C. Crack arrest testing using small wide plate SE(T) specimens. J ASTM Int 2008;5(3). Paper ID JAI101001.

[8] Link Richard E, Joyce James A, Charles Roe. Crack arrest testing of high strength structural steels for naval applications. Engng Fract Mech 2009;76(3):402-18.

[9] Heerens J, Hellmann D. Development of the euro fracture toughness dataset. Engng Fract Mech 2002;69(4):421-50.

[10] Wallin K, Rintamaa R. Master curve based correlation between static initiation toughness, $K_{I C}$ and crack arrest toughness, $K_{I a}$. In: 24 th MPA-seminar, Stuttgart, October 8-9; 1998.

[11] Slater S et al. An energy balance approach for crack arrest, European Commission Technical Steel Research Report, EUR 20952 ; 2004.

[12] Wallin K. Inhomogeneity check of the "EURO" fracture toughness reference data set. In: Advance fracture mechanics of life and safety assessments ECF 15, August 11-13, 2004, Stockholm, Sweden; 2004.

[13] Joyce James A, Gao X. Analysis of material inhomogeneity in the European round robin fracture toughness data set. J ASTM Int 2008;5(9). Paper ID JAI101512.

[14] Gullerud AS, Koppenhoefer KC, Roy A, Dodds Jr RH, Warp3D: 3-D dynamic nonlinear fracture analysis of solids using parallel computers and workstations, Report No. UILU-ENG-95-2012, University of Illinois; February 2004 